\title{
Study on the accumulation process of residual displacement by applying DDA in the Angkor monument, Cambodia
}

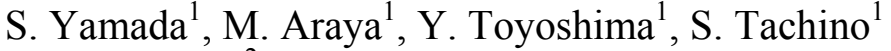 \\ \& T. Miyatani ${ }^{2}$ \\ ${ }^{1}$ Department of Architecture, Faculty of Science \& Engineering, \\ Waseda University, Japan \\ ${ }^{2}$ Microsoft Co. Ltd., Japan
}

\begin{abstract}
In a dry masonry construction, such as the Angkor monument in Cambodia, a residual displacement, which has been accumulated over 1000 years after the construction, is assumed as the essential cause of a tower inclination and collapse. In this paper, applying the discontinuous deformation analysis, DDA, which includes an evaluation of the kinetic friction state after a slide generated between stones in formulization, we conducted a numerical analysis of the Angkor monument focusing on the accumulation process of the residual displacement. Applying DDA, a platform is modeled and the accumulation process of the residual displacement is verified. Then, we verified the relationship between the seasonal accumulation of residual displacement of the platform and the tower inclination, focusing on the phenomenon that the rainy season and the dry season come in the cycle of one year. In addition, to reduce the calculation cost of DDA, we applied a parallel computing to the DDA. Using Microsoft HPC Server 2008 for parallel computing, a numerical analysis of Prasat Suor Prat tower, reflecting the characteristic of masonry construction, was conducted and we compared the displacement and stress distribution calculated by DDA and FEM.
\end{abstract}

Keywords: Angkor monument, DDA, parallel computing, residual displacement, friction test, kinetic friction state, sub soil. 


\section{Introduction}

The Angkor monument is not only a symbol of the traditional culture of the Kingdom of Cambodia and that of the unity of the people, but also a cultural treasure of Asia. However, it is in great danger of destruction now. So, several countries have been carrying out restoration of the Angkor monument. Since 1994, this includes JASA (Japanese Government Team for Safeguarding Angkor and APSARA Safeguarding Angkor), led by Prof. Takeshi Nakagawa (Waseda University, Japan), organized and composed of specialists of various fields. JASA selected the Northern Library of Bayon, Prasat Suor Prat, and the Northern Library inside the Outermost Enclosure of Angkor Wat as targets for the restoration, and conducted various studies and investigations about the structure of these monuments and completed the re-building of those two monuments. Now, JASA is planning the restoration of the Bayon main tower. Our research proposes to evaluate the risk level of the structure and suggests the policy and procedure for the restoration of Bayon.

Preceding our research, the researches of the upper structure, foundation soil and ground were conducted by Prof. Y. Iwasaki (Cyber Univ., Japan) and Dr. M. Fukuda (Higo Geo-Survey Co., Japan). They researched the mechanical effects of various factors, such as wind, water and temperature [1]. In addition, Prof. T. Maeda (Waseda University, Japan) analyzed the structural characteristics of the tower structure connected with the substructure through the vibration behavior with use of the micro-tremor measurement and applied DDA in the Angkor monument [2]. In this paper, we focused on Prasat Suor Prat tower and conducted a numerical analysis by DDA.

\section{Outline of Prasat Suor Prat}

Prasat Suor Prat is located at the Royal Plaza of Angkor Thom. It is believed that it was constructed at the end of the 12th century or the beginning of the 13th century. JASA selected Tower N1 as the most dangerous tower. Then, JASA began the repair and dismantling of Prasat Suor Prat Tower N1 in 2002 and finished the restoration in 2005. The restoration work was conducted by completely dismantling the structural elements, restoring the damaged elements, platform and foundation, and reassembling them to be the original appearance of the tower.

\section{Friction test of laterite and sandstone}

The following friction experiments were conducted for structural analysis considering the friction characteristic between stones. The experiment is a static shear box test of laterite and sandstone. The experiment fixture is shown in Figure 2. A load was measured with a crane scale, and displacement was measured with a dial gauge. When the upper stone was greatly shifted, we ended the experiment. We conducted experiments three times about the combination of each contact surface, considering the stratification of the stone surface. 
The load-displacement curve of laterite and sandstone is shown in Figure 3. The result of the load-displacement curve is summarized as an average of three time experiments by a least squares method. The results of this experiment are the following. 1; Mean value of the laterite's static friction coefficient is 0.73 , and standard deviation is 0.065 . 2; Mean value of the static sandstone's friction

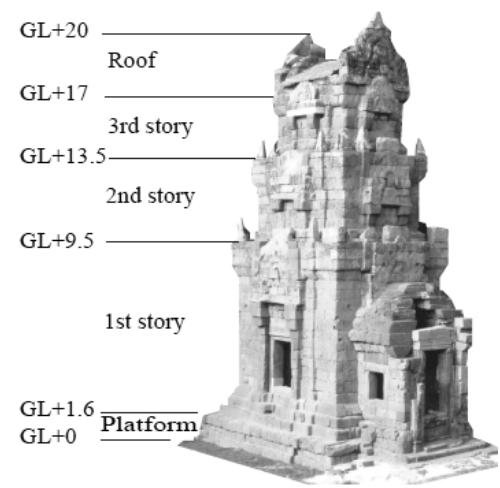

(a)

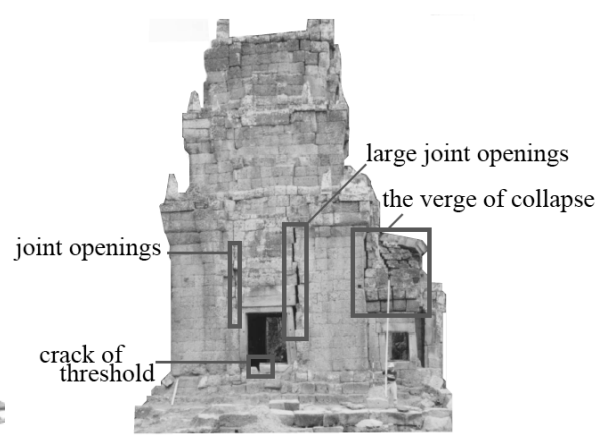

(b)

Figure 1: $\quad$ Prasat Suor Prat tower N1 (a): after restoration; (b): before restoration.

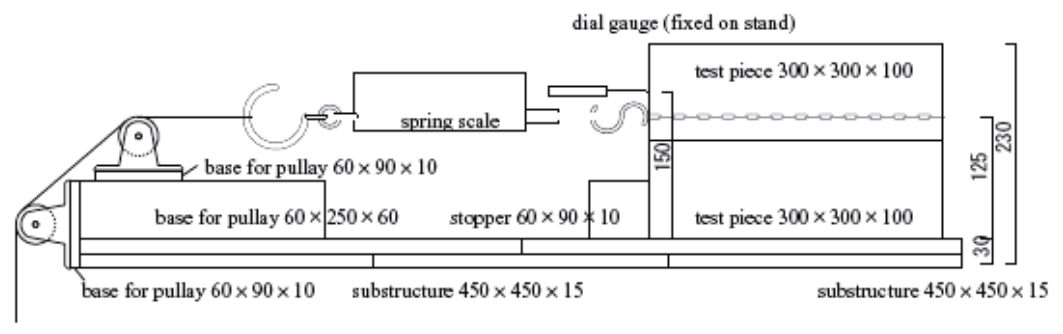

Figure 2: $\quad$ Friction test fixture.

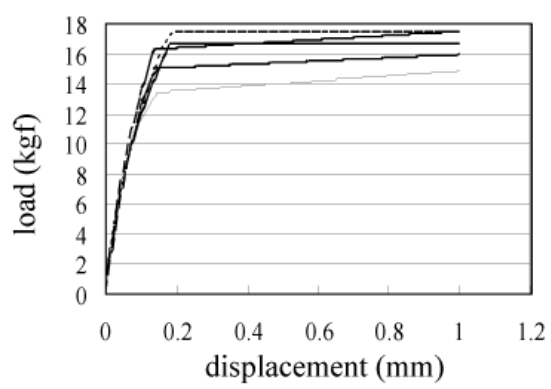

(a)

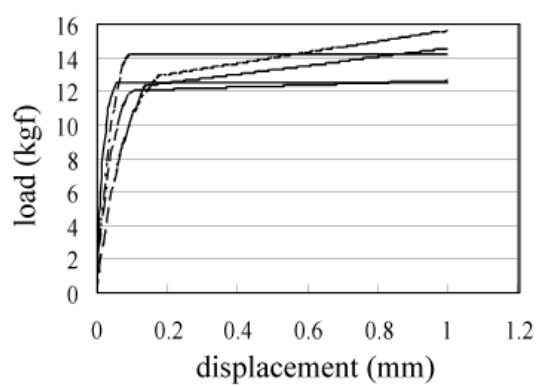

(b)

Figure 3: Load-displacement curve of friction test (a): laterite; (b): sandstone. 
coefficient is 0.62 , and standard deviation is 0.044 . 3; The static friction coefficient in vertical respect of sandstone and laterite does not depend on the stratification. 4; The friction characteristic of laterite and sandstone can be substituted to the bilinear model.

\section{Outline of DDA}

The discontinuous deformation analysis (DDA) is one of the numerical analysis techniques for discontinuous model originated by G.H. Shi [3]. T. Maeda applied DDA to a dry masonry [2]. In DDA, the principal of minimum total potential energy is used for the non-linear equilibrium equation. In addition, the penalty method is used for the displacement constraints, satisfying the no-penetration and no-tension requirements at the contact boundaries. It is a technique suitable for the contact problem and the large displacement problem. In a 3D contact situation, there are six kinds of contact situations, such as point-face, point-line, line-line, line-face, face-face, and point-point. It is proposed that the above contact situations can be classified into two kinds, point-face and line-line, which is adopted in this paper [4]. In this paper, we proposed to add the shear spring for a kinetic friction state, which had a kinetic friction stiffness, in addition to a peak static friction force that operated in the opposite direction to a slide.

\subsection{Applying DDA to the two elements sliding problem}

When applying DDA, we examined a sliding load of laterite and sandstone by simulating the above friction test shown in Figure 2. A load-displacement curve is shown in Figure 4. In the test, the horizontal load was increased by $1 \mathrm{~N}$ per 1 step. As a result, the sliding, in both the models of laterite and sandstone, generated at the mostly theoretical value. Moreover, as shown in Figure 4, it could be simulated that there were different behaviors after the sliding was generated. In reference to the parameter, the penalty stiffness is $2000 \mathrm{kN} / \mathrm{cm}$. In laterite, the static friction coefficient is 0.73 and the kinetic friction stiffness is $0.0637 \mathrm{kN} / \mathrm{cm}$. In sandstone, the static friction coefficient is 0.62 and the kinetic friction stiffness is $0.124 \mathrm{kN} / \mathrm{cm}$. In the uniform motion state after the sliding was generated, the relationship of a kinetic friction stiffness and velocity is shown in Figure 5. In the test, the horizontal load is constant. As shown in Figure 5 , the kinetic friction stiffness and velocity have an inverse proportion relationship by considering the kinetic friction stiffness in this paper.

\section{Numerical analysis of Prasat Suor Prat platform by DDA}

\subsection{Outline of Prasat Suor Prat platform}

The structure below a platform is greatly related as the cause of inclination of Prasat Suor Prat. Before the restoration, Prasat Suor Prat inclined 4.96\% to the Northwest. Uneven subsidence below the platform is considered as the biggest potential cause of the inclination. Uneven subsidence relates to the structure of 
the platform, which is constructed of a sandy foundation surrounded by laterite blocks. Rainwater eroded away the sandy foundation inside the platform and uneven subsidence occurred at the platform. In addition, the strength of the surface layers of the ground greatly differs between the dry season and the rainy season, so remarkable decline of the stiffness in wet conditions causes uneven subsidence. Iwasaki and Fukuda conducted a plate load test on surface layers in dry and wet conditions [1]. Based on their researches, we determined a polynomial of load displacement curve in wet conditions by the least square method (Figure 6). A report about monitoring tower behavior by Iwasaki and Fukuda is as follows.

1) During the rainy season, it inclines in the direction opposite the Northern pond, and conversely, in the dry season, it inclines in the direction of the Northern pond. This movement is elastic and reversible.

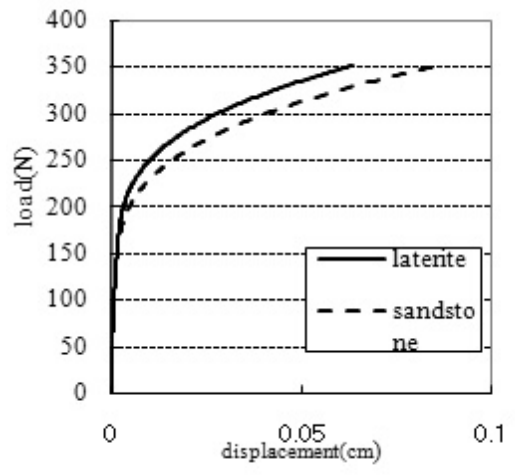

Figure 4: Load-displacement curve of sliding problem.

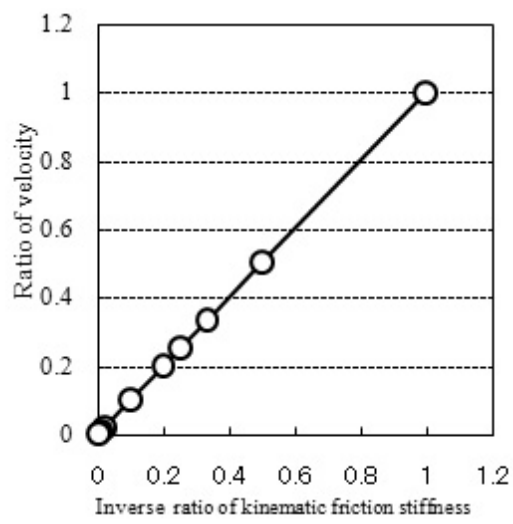

Figure 5: Relationship between kinetic friction stiffness and velocity.

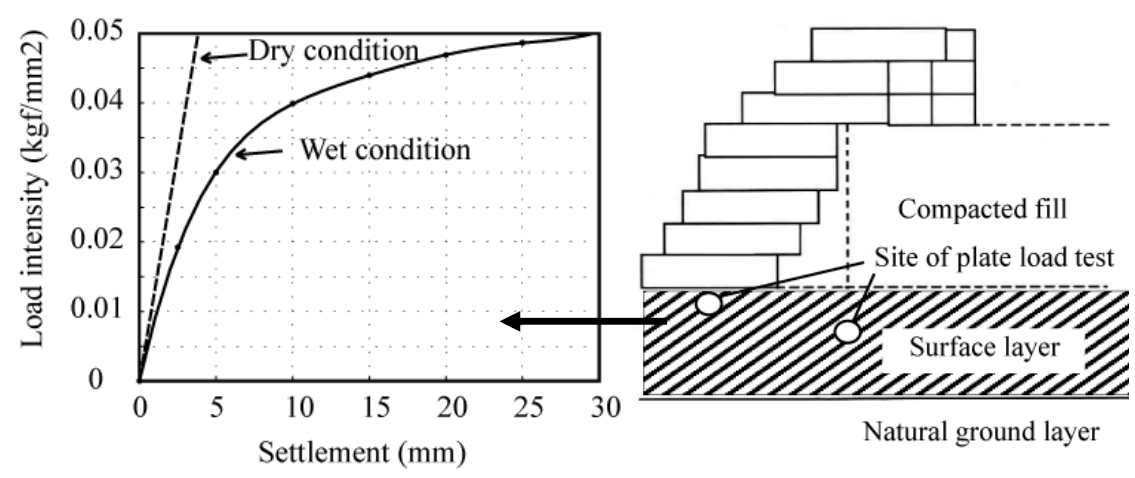

Figure 6: Load-displacement curve of surface layer in dry and wet conditions, and figure of structure below platform. 
2) Plastic deformations occur suddenly in strong winds or rain, and these deformations accumulate. During 1994 to 2002 measurement period, a plastic deformation occurred once due to a heavy downpour on September 26, 1997.

3) The strength of the surface layers greatly differs between the dry season and rainy season, tending to become weak during the rainy season. However, there is hardly any difference between the depths below GL-4m. The natural ground under Tower N1 was around the GL-4m depth.

\subsection{Numerical analysis model of platform}

The platform of Prasat Suor Prat is modeled as Figure 7 and numerical analysis is conducted about the accumulation process of the residual displacement by DDA. In Figure 7, the gray element is a laterite element, and the other white element is a compacted fill inside the platform. And, the depth is modeled as $1 \mathrm{~m}$. As a loading condition, the dead load of the platform and the vertical load and horizontal load from upper structure calculated by FEM are assumed. In reference to the parameter, in laterite, Young's modulus is $2000 \mathrm{kN} / \mathrm{cm}^{2}$, Poisson ratio is 0.25 and density is 2.33. In compacted fill, Young's modulus is 2.8 $\mathrm{kN} / \mathrm{cm}^{2}$, Poisson ratio is 0.3 and density is 1.75 . As DDA parameter, a penalty stiffness is $2000 \mathrm{kN} / \mathrm{cm}$, static friction coefficient is 0.73 and kinetic friction stiffness is $0.0637 \mathrm{kN} / \mathrm{cm}$. At the undersurface of the model, the spring which modeled the sandy soil of the subsurface layer is added based on the plate load test in a dry and wet condition. About the spring characteristic, it is assumed that the dry condition is a linear characteristic and the wet condition is a nonlinear characteristic (Figure 6). We verified the accumulation process of the residual displacement proceeded by changing spring characteristic with the dry condition and the wet condition. To change the spring characteristic with a dry and wet

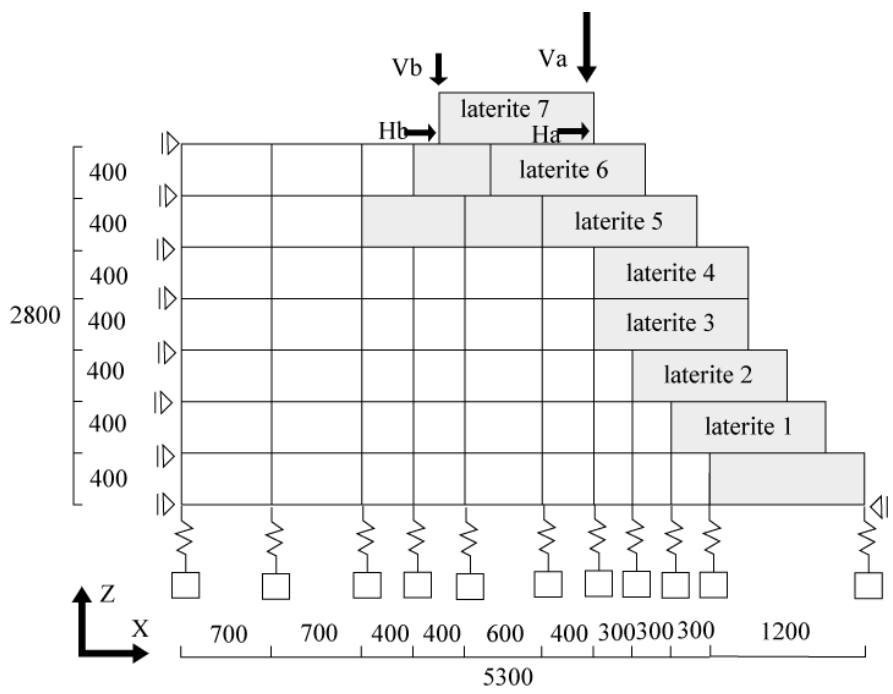

Figure 7: $\quad$ DDA model of platform. 
condition means the consideration of the subsurface layer characteristic which is greatly different in the rainy season and the dry season in one year. Namely, we conducted a numerical analysis about the phenomenon which the spring characteristic changed in the cycle of one year.

\subsection{Numerical analysis result}

When the spring characteristic is changed continuously, each progress of displacement of $\mathrm{X}$ direction, $\mathrm{Z}$ direction in laterite element 1 to 7 is shown in Figure 8. About the displacement of $\mathrm{X}$ direction, when it is changed from dry condition of $1 \mathrm{st}$ step to wet condition of 2 nd step, about $13 \mathrm{~mm}$ residual displacement was generated in laterite 1 , and about $3 \mathrm{~mm}$ residual displacement was generated in laterite 2 . After 2 nd step, in laterite 1 and laterite 2 , the residual displacement didn't progress approximately. About the displacement of $\mathrm{Z}$ direction, the elastic heave movement of about $1 \mathrm{~mm}$ is repeated until 10th step. About rotation Ry, although the elastic movement is repeated until 10th step, the rotation angle is increasing in the direction of (-)Ry slightly in laterite 2 to 7.

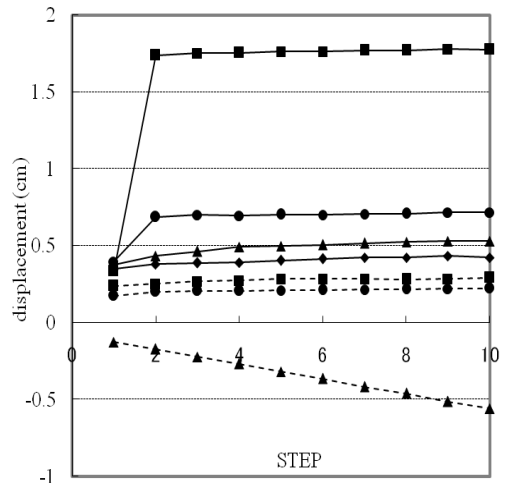

(a)

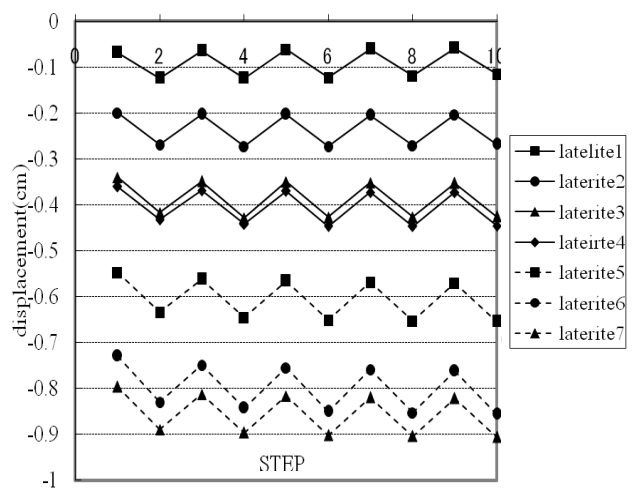

(b)

Figure 8: $\quad$ Progress of residual displacement (a): X direction; (b): Z direction.
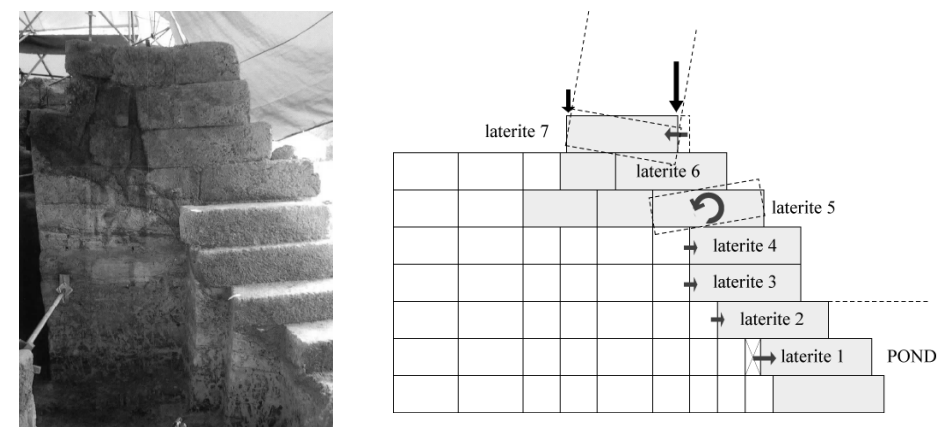

Figure 9: Diagram of relationship of horizontal displacement and tower inclination. 


\subsection{Consideration}

From the numerical analysis result, we confirmed about the accumulation process of the residual displacement to a horizontal direction in the lower layer of platform laterite. We propose that the accumulation of the residual displacement is a highly probable cause of tower inclination. About platform structure, we propose that the horizontal physical relationship of laterite 7 , laterite 5, and laterite 1 is important, that is, it is a moment weight of laterite 5. There is a correlation between rotation angle of laterite 5 by the moment weight and tower inclination. Without restraint to a horizontal direction by the existence of the pond, the tower inclination to the pond is increased in tower N1. That there is no restraint to a horizontal direction means that the lower layer of platform is displaced horizontally. It also makes the moment weight of laterite 5 increase and it is surmised that a tower inclination is caused.

\section{Numerical analysis of Prasat Suor Prat tower by parallel computing of DDA}

\subsection{Outline of parallel computing of DDA}

In DDA, as the number of elements is increased, the number of contact judgment is increased in series. When we conduct a time history response analysis and convergence calculation at each step, a computational complexity is huge. A part which costs much computation time is a part of a contact judgment and preparation of a sub matrix by contact at each contact point, so we decided to incorporate a parallel computing into this part. As a parallel computing environment, Windows HPC Server 2008 (16workers) in Microsoft Innovation Center was used. And, programming of DDA and the parallel computing were performed by using the programming software Matlab and Matlab Distributed Computing Server. In a certain calculation interval, a comparison of the calculation speed from 1 to 16 workers by the parallel computing of DDA is shown in Figure 10.
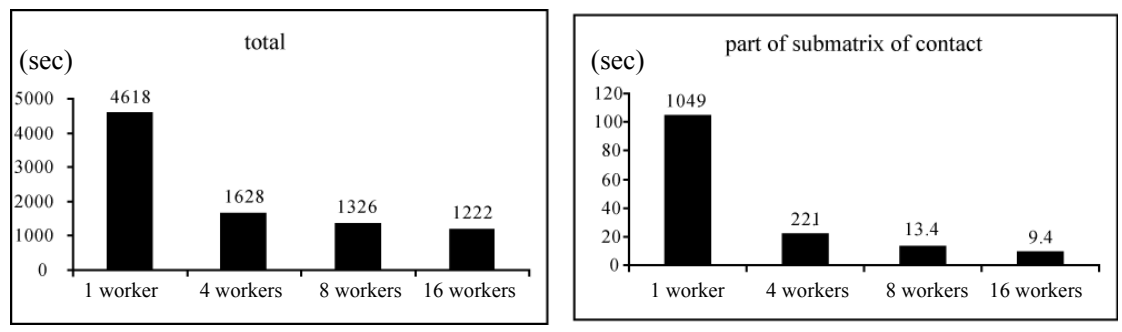

Figure 10: Comparison of calculation time in different number of workers. 


\subsection{Numerical analysis model of the tower}

A tower displacement behavior is verified by using DDA. About the platform, it is simplified as shown in Figure 11, but we assumed that there was an enough rationality of simplifying from the result of Section 5. And, a masonry construction in the model of the tower is also simplified, but we assumed that it was appropriate because of the observed state and masonry construction. At the undersurface of the model, the spring which modeled the sandy soil of the subsurface layer in dry condition is added. And, the parameter of numerical analysis is same as the Section 5.

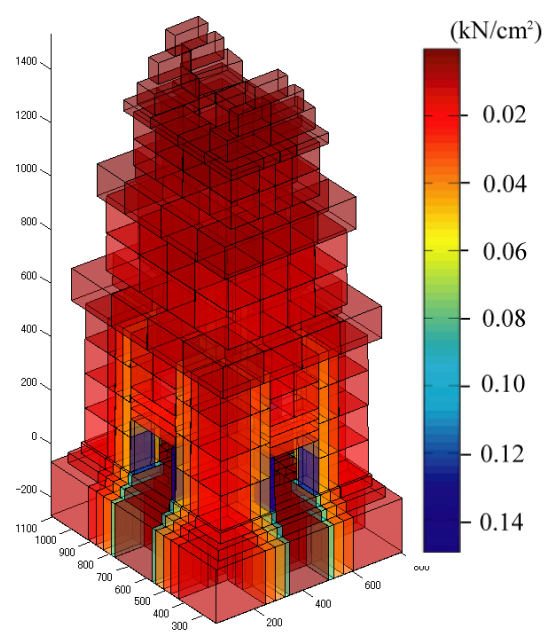

(a)

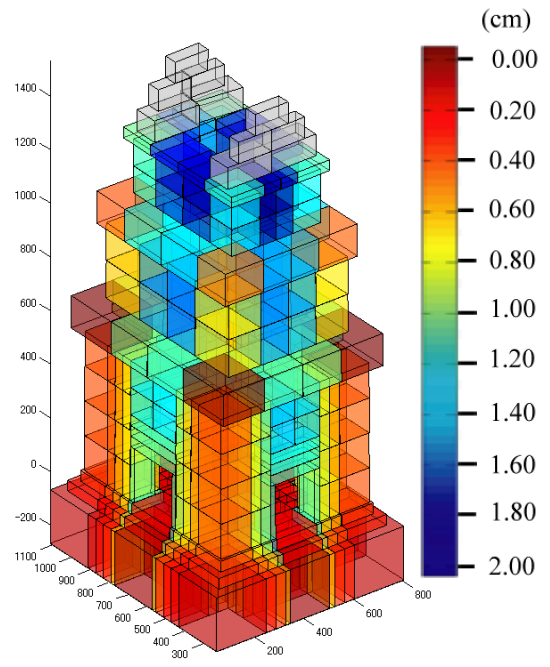

(b)

Figure 11: Fixture of DDA result (a): vertical stress $\sigma z z ;(b)$ : vertical displacement Uz.

Table 1: $\quad$ Comparison of displacement analyzed by DDA and FEM.

\begin{tabular}{|c|c|c|c|c|}
\hline & & DDA & FEM & DDA/FEM \\
\hline \multirow{3}{*}{ 1st story } & $\mathrm{Uz}(\mathrm{cm})$ & 0.938 & 0.0464 & 20.2 \\
\cline { 2 - 5 } & $\mathrm{Ux}(\mathrm{cm})$ & 0.775 & 0.0237 & 32.7 \\
\cline { 2 - 5 } & $\mathrm{Uy}(\mathrm{cm})$ & 0.786 & 0.0464 & 16.9 \\
\hline \multirow{3}{*}{ 2nd story } & $\mathrm{Uz}(\mathrm{cm})$ & 1.580 & 0.269 & 5.9 \\
\cline { 2 - 5 } & $\mathrm{Ux}(\mathrm{cm})$ & 0.663 & 0.00504 & 131.5 \\
\cline { 2 - 5 } & $\mathrm{Uy}(\mathrm{cm})$ & 1.090 & 0.0457 & 23.9 \\
\hline \multirow{3}{*}{ 3rd story } & $\mathrm{Uz}(\mathrm{cm})$ & 2.040 & 0.292 & 7.0 \\
\cline { 2 - 5 } & $\mathrm{Ux}(\mathrm{cm})$ & 0.933 & 0.00336 & 277.7 \\
\cline { 2 - 5 } & $\mathrm{Uy}(\mathrm{cm})$ & 1.950 & 0.0516 & 37.8 \\
\hline
\end{tabular}




\subsection{Numerical analysis result}

From the result, the stress concentration at the pillar of the door and the stress distribution generated by the masonry construction are represented in Figure 11. As shown in Figure 11, a tower displacement behavior which is unable to be simulated in continuous model is represented. In the concrete, it is that the vertical displacement of the upper area of the door is relatively large, and the displacement by the rotation to the center of the tower is large.

At 1st story, 2nd story, and 3rd story, the maximum of each displacement calculated by DDA is compared with the displacement calculated by FEM based on continuous model (Table 1). As compared with FEM, it is resulted that DDA evaluates each displacement greatly.

\section{Conclusions}

Based on the past monitoring and stone's friction test, the accumulation process of the residual displacement of the platform of Prasat Suor Prat was verified by DDA, and we considered about the cause of the tower inclination. Applying a parallel computing to DDA, we assessed the stress and displacement of the tower in consideration of the characteristics of a masonry construction and platform. We confirmed that the displacement and stress distribution had a large difference between DDA and FEM. As a future subject, a reduction of calculation cost can be realized by improving the algorithm of DDA.

\section{Acknowledgements}

The work presented in this paper forms the part of the work carried out by JASA. We are grateful to JASA for their support and management, especially Prof. T. Nakagawa (Waseda Univ., Japan). We are also grateful to Prof. Y. Iwasaki (Cyber Univ., Japan) and Dr. M. Fukuda (Higo Geo-Survey Co., Japan) for their technical advices.

\section{References}

[1] T. Nakagawa et al., Report on the Conservation and Restoration Work of the Prasat Suor Prat Tower, JASA: Tokyo, pp127-196, 2005

[2] T. Maeda, T. Yamamoto, Continuous and discontinuous modeling of the structures in Bayon temple, Angkor, Proceedings of the Sixth international Conference on Structural Analysis of Historic Construction, Vol.1, pp.629634, 2008

[3] Jian-Hong Wu, Yuzo Ohnishi, Satoshi Nishizawa, Gen-Hua SHI, Theory of Three-Dimensional Discontinuous Deformation Analysis and Its Application to a Slope Toppling at Amatoribashi, Japan, International Journal of Geomechanics, Vol.5 No.3 pp.179-195,2005 
[4] Q.H. Jiang, M.R. Yeung, A Model of Point to Face Contact for three dimensional Discontinuous Deformation Analysis, Rock Mechanics and Rock Engineering, pp95-116, Austria 